\title{
Identifying opportunities for supporting caregivers of persons with dementia through information and communication technology
}

\author{
J.E. McHugh PhD \\ J.P. Wherton $\mathrm{PhD}$ \\ D.K. Prendergast PhD \\ B.A. Lawlor MD FRCPsych \\ Technology Research for Independent Living Centre, \\ Trinity College Dublin, Ireland \\ E: mchughje@tcd.ie
}

\begin{abstract}
J.E. McHugh, J.P. Wherton, D.K. Prendergast, B.A. Lawlor. Identifying opportunities for supporting caregivers of persons with dementia through information and communication technology. Gerontechnology 2012; 10(4):220-230; doi:10.4017/gt.2012.10.4.003.00 With the demographic shift towards an older population, the contribution made by informal caregivers of persons with dementia is becoming increasingly important. The ongoing demands of the caring role can often impact mental health and physical well-being. Information and communication technology (ICT) may offer new ways of reducing caregiver burden through information provision and social contact. Interviews were conducted with 14 spouse caregivers of persons with dementia. Grounded theory analysis of interview transcripts revealed specific areas where ICT could help. These are summarised under three main themes: 'Support needed' (education and informal), 'social isolation' (leaving the house and sustaining networks) and the 'relationship' between patient and caregiver (disappearance and interaction). The findings demonstrate the importance of consulting caregivers to ensure that technology design is grounded in an understanding of the problems being addressed.
\end{abstract}

Keywords: caregiver, dementia, technology, ICT, grounded theory analysis, design

Progressive decline in functional status of persons with dementia is emotionally and financially exhausting for caregivers. The role of the caregiver role starts with assistance with relatively complex tasks, and progresses to include the provision of ongoing assistance with more fundamental activities of daily living, as well as dealing with personality changes and behavioural disturbances ${ }^{1}$. One in five people over 80 and one in 20 over the age of 65 suffer from a form of dementia ${ }^{2}$. Our ageing population means that prevalence of dementia will increase, without a planned proportionate rise in professional care. Therefore the role of the family caregiver will become increasingly important in minimising the strain on health care services. The burden on the caregiver contributes to levels of stress and depression, which is found to be a strong predictor for patient referral into institutionalised settings ${ }^{3}$. Therefore, addressing caregiver consequences not only affects their perceived ability to cope, but also plays an important role in helping people with dementia remain at home for longer and reducing cost to health care systems.

Caring for someone with dementia can lead to depression, sleep disturbance, anxiety and 


\section{Caregivers and $\| C T$}

loss of companionship. Difficulties in dealing with behavioural problems, aggression and incontinence can also contribute to the stress $^{1,4,5}$. Caregivers experience greater susceptibility to illness and frequently neglect their own health as a result of the care demands ${ }^{6}$. Additionally, confinement to the home, loss of autonomy and decreased participation in social activities further impacts mental health and perceived ability to cope $\mathrm{e}^{7-9}$.

Numerous studies have demonstrated the benefits of peer supports, education groups and skill training for caregivers. These may include interventional workshops providing information about dementia, available services and coping strategies ${ }^{10,11}$. Others include peer- or professional-led group meetings to discuss problems and exchange of ideas ${ }^{12}$. However, geographical distance, time constraints and availability of professional resources limit the accessibility of such programmes. To overcome these constraints, the use of information and communication technology (ICT) for caregivers has been explored. Examples include ComputerLink $^{13}$, the REACH computer-integrated telephone system (CTIS $\left.{ }^{14}\right)$; AlzOnline ${ }^{15}$, Caring for Others ${ }^{16}$ and the DEM-DISC (DEMentia Digital Interactive Social $\mathrm{Chart}^{17}$ ). These schemes usually include an online information resource related to dementia care and local services, which can be accessed using simple search tools $\mathrm{s}^{13-15,17}$. Other schemes have used online question and answer forums or educational classes ${ }^{13,15}$. Telephone conferencing has also been used to allow caregivers to discuss topics and share experiences $^{14,16}$. These studies have shown positive outcomes, including improved decision confidence, self-efficacy, mood and stress ${ }^{13-16}$.

In summary, numerous ICT solutions have been developed to support caregivers of persons with dementia. These involve different approaches to providing educational content about dementia and local services, as well as opportunities for professional and peer support. In these approaches, design requirements have been typically generated in a top-down fashion, rather than being user-led. As such it is less clear what caregivers themselves actually want from such technology. Powell, Chiu and Eysenbach ${ }^{18}$ investigated the perspective of informal caregivers (for instance, spouse, son or daughter, grandson or -daughter, friend) in relation to ICT, including telecare and internet-based resources. The analysis provided a broad insight into the requirements of such technology, highlighting, for example, the need to address concerns around impersonality of technology, risk of information overload and importance of augmenting existing services rather than replacing them. The current study aimed to understand the problems experienced by caregivers, focusing on the spouse or partner living with the person with dementia. Home visit interviews were conducted with caregivers in their own homes to identify opportunities for support. A qualitative "grounded" approach ${ }^{19}$ was taken to characterise interviews. This involved transcription of interview data and identification of themes that reflect the participants' perspectives. This approach has previously been found to be useful for establishing technological opportunities to support persons with dementia on daily tasks ${ }^{20}$. Extracts from the interview transcripts and the opportunities for supporting caregivers through ICT are presented in the discussion.

\section{Method \\ Sample}

Fourteen caregivers were recruited from two sources, the TRIL Clinic and the Memory Clinic, both at St James's Hospital, Dublin. The sample were an opportunistic group of caregivers linked in to the Memory Clinic and TRIL Clinic. All participants were older adults and were a spouse to a person with dementia living at home. The level of dementia ranged from mild to severe across the sample. The group were purposefully heterogeneous in terms of dementia to give us an understanding of the support needs of caregivers at all stages of dementia care. Eight of the caregivers were male and six were female. All participants lived in Dublin and its surrounding areas. All care recipients were living at home and care was based 


\section{Caregivers and ICT}

in the home, excepting some intermittent respite received. The age range was 54-82 years. All participants were provided with an information sheet describing the purpose of the project and provided written consent to take part. The study was approved by St James's Hospital Research Ethics Committee.

\section{Procedure}

The majority of interviews took part in the participants' homes. Two interviews took place in St James's Hospital at the request of the participant. Before the interview started the researcher explained the research objective and the purpose of the interview. The protocol was a semi-structured interview focusing on participants' role as caregiver, how it has impacted their daily routine and social activities, and how technology might help. Each interview lasted approximately one hour. All interviews were audio recorded and transcribed for analysis. One participant requested that his interview was not recorded, and therefore the data presented are based on transcriptions from 13 interviews.

\section{Analysis}

All interview transcripts were analysed using grounded theory analysis $\left(\mathrm{GTA}^{19}\right)$. The first stage (open coding) involved reading the material and identifying component concepts of what participants talk about. The second phase of the analysis (axial coding) involved grouping related concepts together to form categories and subcategories. The third stage of analysis (selected coding) involved grouping the main categories into broader themes.

\section{Results}

Open coding revealed 16 subcategories, for instance, guilt about socialising, confrontation and communication. Transcripts and the number of occurrences are shown (Table 1), as well as the organisation of the subcategories, achieved through axial and selected coding (Table 2). The subcategories represent the language used by our participants. The first theme was labelled 'support needs', which includes 'educational and informal supports'. The second theme relates to 'so- cial isolation', which includes problems with 'sustaining networks' and difficulties 'leaving the house'. The third theme describes issues related to the patient-caregiver 'relationship', which includes 'disappearance' of the relationship and 'interaction' between them.

\section{Discussion}

The characterisation of our participants' accounts will be useful for designing ICT to support caregivers in the home (Table 1). First, we will focus on how ICT can support the caregiver role. Subsequently issues are treated related to social isolation and the impact of these on ICT design. In the last section we will consider possibilities for ICT supporting the patient-caregiver relationship. These issues will be discussed in relation to existing technologies and how they could be further developed to suit the needs of the users.

\section{Support needs}

\section{Educational}

Participants felt the need to access information about dementia, increase their knowledge about local services available and learn how to deal with the change to their life. For those who used a computer, the internet was a useful source of information, though it is difficult to manage the large volume of material and identify what is relevant to them. One caregiver who has access to the internet described the difficulty in searching through relevant material; "There's so much material, so many bits of it to be put together, like an enormous jigsaw, but the only difference is that the pieces keep changing, so you're never quite sure what's going to fit". Another caregiver, who was less likely to use the internet, talked about the difficulties in accessing any relevant information via other means; "I find that there's not a lot of information in the public domain ...nothing in the papers. Even if there's been a small breakthrough or anything like that, it can be at times very frustrating".

\section{Previous educational research}

These statements highlight the need to maintain a balance between sufficient information provision and simplicity for ease of use. 
Table 1. Subcategories that emerged from the open coding. Each subcategory presents the example extract, the number of instances it occurred and the number of transcripts it occurred in $(n=13)$

\begin{tabular}{|c|c|c|c|}
\hline \multirow{2}{*}{ Category } & \multicolumn{2}{|c|}{ Occurrence } & \multirow{2}{*}{-Example extract } \\
\hline & Instances & Transcripts & \\
\hline Dependence & 27 & 9 & $\begin{array}{l}\text { "So it's like moving from a relationship of } \\
\text { interdependence, to one where the other person is } \\
\text { dependent. Now that has enormous implications" }\end{array}$ \\
\hline $\begin{array}{l}\text { Change in } \\
\text { personality }\end{array}$ & 19 & 7 & $\begin{array}{l}\text { "Not the same person I married. That's the way it is, } \\
\text { she's a different person and I can't get inside her head } \\
\text { to know what she's thinking or what she's like" }\end{array}$ \\
\hline Communication & 19 & 7 & $\begin{array}{l}\text { "It interferes with your emotional relationship, it } \\
\text { interferes with, it's very hard 'cos our relationship } \\
\text { obviously has suffered because I get nothing back" }\end{array}$ \\
\hline Practical support & 18 & 9 & "Our daughters come every day and do the shopping" \\
\hline Loss of interest & 18 & 8 & $\begin{array}{l}\text { "I need to keep her busy, I need to keep her alive and } \\
\text { focused and all of that" }\end{array}$ \\
\hline $\begin{array}{l}\text { Mentor / } \\
\text { Reassurance }\end{array}$ & 12 & 6 & $\begin{array}{l}\text { "Sometimes you need someone to say you know, you're } \\
\text { doing a great job, keep at it" }\end{array}$ \\
\hline Tied to house & 11 & 5 & $\begin{array}{l}\text { "I better not go out because I was afraid of her, she did } \\
\text { fall two or three times now, just fell down" }\end{array}$ \\
\hline $\begin{array}{l}\text { Confusion } \\
\text { outside }\end{array}$ & 10 & 6 & $\begin{array}{l}\text { "If we were in a supermarket or a department store and } \\
\text { I go somewhere, it's just a moment, a split of a second } \\
\text { and she's gone" }\end{array}$ \\
\hline Patient withdraw & 10 & 6 & $\begin{array}{l}\text { "She became over a period of } 4 \text { or } 5 \text { years, distant from } \\
\text { some people, that she was quite friendly with, they } \\
\text { experienced her as withdrawing and they didn't } \\
\text { understand why" }\end{array}$ \\
\hline $\begin{array}{l}\text { Services / Local } \\
\text { projects }\end{array}$ & 9 & 5 & $\begin{array}{l}\text { "Any news about that whole area or whatever, nursing } \\
\text { homes or daycare centres, would all be of interest, you } \\
\text { know, to people who are in that condition. It could } \\
\text { have an advantage, it might force us to communicate } \\
\text { more" }\end{array}$ \\
\hline $\begin{array}{l}\text { Public } \\
\text { perceptions }\end{array}$ & 9 & 5 & $\begin{array}{l}\text { "I find partly when I'm out with her it's a bit } \\
\text { embarrassing because she'd be saying "there there } \\
\text { there", not very loud but you know" }\end{array}$ \\
\hline Manage change & 9 & 4 & $\begin{array}{l}\text { "There's so much material, so many bits of it to be put } \\
\text { together, like an enormous jigsaw, but the only } \\
\text { difference is that the pieces keep changing, so you're } \\
\text { never quite sure what's gonna fit because it's like a } \\
\text { dynamic jigsaw". }\end{array}$ \\
\hline Outlet & 9 & 4 & $\begin{array}{l}\text { "I get terrified that it becomes a record, I say oh Christ, I } \\
\text { say to people, stop me if I've told you this already, I } \\
\text { can't remember who I told what to you know?" }\end{array}$ \\
\hline $\begin{array}{l}\text { Information and } \\
\text { new } \\
\text { developments }\end{array}$ & 7 & 5 & $\begin{array}{l}\text { "I find that there's not a lot of information in the public } \\
\text { domain for...nothing in the papers. Even if there's been } \\
\text { a small breakthrough or anything like that, it can be at } \\
\text { times very frustrating" }\end{array}$ \\
\hline Confrontation & 6 & 3 & $\begin{array}{l}\text { "It'll go nowhere because that triggers her aggressive } \\
\text { mood" }\end{array}$ \\
\hline Guilt socialising & 4 & 3 & $\begin{array}{l}\text { "If she's in here on her own, and I'm out there, she gets } \\
\text { a bit depressed, you know. And she wouldn't go } \\
\text { out...sometimes I do feel guilty about going out, I must } \\
\text { say" }\end{array}$ \\
\hline
\end{tabular}


Table 2. A summary of the themes, categories, sub-categories and design principles that emerged from the grounded theory analysis

\begin{tabular}{|c|c|c|c|}
\hline Theme & Category & Sub-category & Design principle \\
\hline Support need & Educational & $\begin{array}{l}\text { Information and new } \\
\text { developments } \\
\text { Services and local } \\
\text { projects } \\
\text { Managing change } \\
\text { Offload feelings } \\
\text { Mentoring and } \\
\text { reassurance } \\
\text { Practical support }\end{array}$ & $\begin{array}{l}\text { Provide on-demand educational } \\
\text { content focusing on development } \\
\text { in dementia care and services, } \\
\text { available resources and self-care. } \\
\text { Provide a flexible and non- } \\
\text { intrusive channel for caregivers to } \\
\text { discuss issues and share } \\
\text { knowledge. } \\
\text { This must be fit the ongoing } \\
\text { changes to the caregivers' daily } \\
\text { routines. }\end{array}$ \\
\hline Social isolation & $\begin{array}{l}\text { Difficulty leaving the } \\
\text { house }\end{array}$ & $\begin{array}{l}\text { Tied to the house } \\
\text { Confusion outside the } \\
\text { home } \\
\text { Public perceptions of } \\
\text { dementia } \\
\text { Patient withdrawing } \\
\text { from social networks } \\
\text { Carers' guilt about } \\
\text { socialising }\end{array}$ & $\begin{array}{l}\text { ICT to help caregivers and } \\
\text { persons with dementia feel } \\
\text { connected with the wider } \\
\text { community. } \\
\text { Technology that provides } \\
\text { reassurance to the caregiver } \\
\text { about the patient's well-being } \\
\text { will provide greater freedom } \\
\text { to leave the house. } \\
\text { ICT providing fun and engaging } \\
\text { tools to help caregiver and } \\
\text { patient remain connected with } \\
\text { broader social network. } \\
\text { Social presence technologies to } \\
\text { encourage other members of } \\
\text { social network to maintain } \\
\text { regular contact with caregiver, } \\
\text { and nonintrusive tools to check- } \\
\text { in with each other. }\end{array}$ \\
\hline Relationship & Interaction & $\begin{array}{l}\text { Personality changes of } \\
\text { patient } \\
\text { Confrontation } \\
\text { Dependence } \\
\text { Communication } \\
\text { Loss of interest }\end{array}$ & $\begin{array}{l}\text { Support communication and } \\
\text { shared experience by exploiting } \\
\text { preserved memories of person } \\
\text { with dementia (for instance, } \\
\text { reminiscence). } \\
\text { A shared interface that allows } \\
\text { both carer and patient to enjoy } \\
\text { entertaining displays that are not } \\
\text { cognitively demanding (for } \\
\text { instance, video footage of public } \\
\text { spaces such as park or zoo). }\end{array}$ \\
\hline
\end{tabular}

A number of ICT interventions have been developed that provide educational material and guide users towards information that is relevant to them. ComputerLink provided 'decision-support' through a series of questions related to their needs. Questions would appear on the screen (for instance, whether to get a home health program) followed by questions related to aspects on which the decision would be evaluated (for instance, cost, availibility) and their relative importance. Similarly, Van de Roest et al. ${ }^{17}$ piloted an internet resource for caregivers, the DEM-DISC, which provides caregivers with customised information about care needs and relevant services in their region. The system uses a search engine that is designed to guide the users in clarifying their 


\section{Caregivers and $\| C T$}

needs into specific demands. Our findings confirm the importance of these tools. However, they also highlight a need to broaden the scope of these tools to help caregivers manage their own mental and physical well-being. One caregiver emphasised the difficulties in monitoring their own wellbeing when dedicating much of the time to support the other person; "I am so emotionally and physically drained I haven't actually time to think about myself". Caregivers are more likely to experience inadequate sleep, self-care, nutrition and physical exercise ${ }^{21-23}$. ICT should also target these issues and help caregivers adapt to the changing situation.

\section{Informal}

Informal networks were considered a valuable source of practical help (for instance, doing the shopping) and to 'offload' feelings and concerns. However, these channels of support were not always utilised due to concerns that overuse could impact friendships; "You have to offload something but you don't want to be the one that, here she comes...you can't spend the whole time talking about it". Caregivers were also conscious of preserving their partner's dignity, and some would avoid discussing problems with mutual friends; "I don't want to drag attention to it because it probably would upset him. If he knew that they know".

It was generally believed that contact with other caregivers would provide opportunities for 'mentoring and reassurance'. The common ground and shared experience provide emotional support and also offer opportunities to learn from the experience of others; "Reassurance to know that there are other people in that boat, you might meet or talk to somebody that just had that particular experience...might have been through it and tell how you dealt with it". Interaction with other caregivers might also provide opportunities for positive encouragement and boost motivation: "Sometimes you need someone to say you're doing a great job, keep at it, so maybe just some reinforcement of, maybe just some positive things".
Previous 'informal' research

These points highlight the possibility of supporting caregivers through ICT beyond education and information provision. Research has found that knowledge about dementia can in fact increase desire to institutionalise (DIS) the person with dementia, and so education alone may not be helpful in reducing caregiver burden ${ }^{24}$. There is increasing evidence showing that caregiver self-efficacy is a key factor in minimising burden ${ }^{25}$. According to social learning theory, self-efficacy is the belief that one can perform a specific task, and is a psychological attribute that can be learned and enhanced. Self-efficacy can increase perseverance, improve resilience and influence perceived difficulty or burden of a task ${ }^{26}$. Previous ICT solutions have used group forums and conference call systems for weekly or monthly peer-support meetings ${ }^{14,16}$. Designing such systems to enable caregivers to learn about the achievements of others (known as 'vicarious experience') and receive encouragement and positive feedback ('verbal persuasion') may help improve caregiver self-efficacy.

\section{Social Isolation}

Difficulty leaving the house

It is well documented that the demands of the caregiver role, particularly issues related to behavioural problems and functional impairment, limit opportunities for social interaction $^{27-29}$. Participants often reported a sense of being 'tied to the house' due to ongoing care demands and need to maintain a consistent routine: "I've to stick with that routine and get her ready to go and collect her in the evenings. So I can't just breeze off". Caregivers also highlighted that concerns about the patient's safety (for instance, falling, wandering or cooker safety) also restricted their movements; "Can't leave her in the house, with the cooker and everything". Constraints for the caregiver also apply outside the home, in which problems may arise when both caregiver and spouse leave the house together. Participants reported the difficulties experienced if the person with dementia becomes 'confused' in public spaces and starts wandering or getting lost; "But the other day this was 


\section{Caregivers and $\| C T$}

the very first time, I came out and he wasn't in the car and I couldn't see him anywhere"; and also "If we were in a supermarket or a department store and I go somewhere, it's just a moment, a split of a second and she's gone".

There was also some concern about perception of others towards their partner's behaviours in public places; "I've often found other older people without the condition do be staring at her when she's out and being odd or whatever". Similarly, caregivers also described how behavioural or memory problems can cause difficulties when meeting people they know; "They were great friends, and she said to him, how is your wife, and she was 3 years dead! And he looked at me and said, what's going on?"

\section{Previous 'out of the house' research}

Home based telecare and assistive technology (for instance, memory aids, fall detectors and cooker sensors) go some way to reducing care demands ${ }^{30,31}$. Although progress is being made with these developments, ICT must ensure that it is flexible enough to match the constraints placed on the caregiver. For example, online conference calls must be compatible with ongoing, and often unpredictable, time constraints. Others have highlighted the issue of 'social obligation' in using ICT for social participation, and the need for systems to support 'opportunistic' $^{\prime}$ social encounters ${ }^{32}$. This approach may be well suited to caregivers who may find it difficult to commit to scheduled meetings. Mobile technologies also offer opportunities for greater flexibility in terms of location. The current ICT solutions for caregivers involve personal computers or static telephones. Developments in portable devices and smart phones offer new opportunities to develop ICT that is flexible and mobile enough for caregivers to incorporate into their everyday routines. More work is needed to explore how ICT can be provided to caregivers in an unobtrusive and private fashion.

\section{Sustaining social networks}

Difficulty sustaining existing social networks was a common category found in the inter- view transcripts. This was partly attributed to patients' social withdrawal, in which they would lose motivation or interest in going out or socialising: "She became over a period of 4 or 5 years, distant from some people, that she was quite friendly with, they experienced her as withdrawing and they didn't understand why"; "She says she has no friends but, sometimes she doesn't want to go out, and she forgets that".

This guilt would also impact the caregiver's social activity, as they may feel guilty leaving the person with dementia alone when they socialise without them; "If she's in here on her own, and I'm out there, she gets a bit depressed, you know. And she wouldn't go out...sometimes I do feel guilty about going out".

Previous 'sustaining social networks' research These issues highlight the other constraints placed on the caregiver in addition to the more practical issues (for instance, safety and dependency). Therefore, ICT should extend beyond the instrumental and emotional benefits of social support, to also provide opportunities for social engagement with their broader social networks. Lightweight modes of communication (for instance, messaging and photo-sharing) provide new ways of increasing a sense of social presence and social connectedness in unobtrusive ways. Recent work into 'social presence displays' and 'awareness systems' also shows further possibilities in helping people to effortlessly maintain awareness of each other. These systems are typically always on, have limited functionality and communicate another persons' location or activities. The aim of these systems is to provide reassurance, let others know you are thinking about them and encourage or create opportunities for communication. An example display is the 'intentional presence lamp' which lights up when remotely located individuals want to indicate their presence at home ${ }^{33}$. The 'digital family portrait' developed at Georgia Tech was designed to increase family members' awareness of their senior relatives' day-to-day activities using subtle icons on a 


\section{Caregivers and $\| C T$}

picture frame. Awareness displays such as these may help caregivers to remain socially connected with their broader social network $^{34}$ or act as catalysts for social engagement ${ }^{35}$. It is clear from the above examples that ICT can not only support caregivers through information provision and peersupport, but can also provide social benefit by facilitating communication and helping them sustain their social network.

\section{Relationship}

The third theme relates to the specific social interaction between the caregiver and the person with dementia. Participants reported a 'disappearance' of the relationship. This was due to personality changes in the person with dementia and the desire to avoid distress or confrontations; "Most carers are either partners, siblings, there's a relationship there, and I'm saying, where's that now? I'm not sure. I don't hear much about that"; "Not the same person I married. That's the way it is, she's a different person and I can't get inside her head to know what she's thinking or what she's like".

Communication difficulties (for instance, word finding, following conversations and remembering what was said) made it difficult to have a conversation and reduced caregivers' motivation to talk with their spouse; "I'm not inclined to say much to her, I say what's the point sometimes, sometimes I will involve her, but two minutes later she's forgotten".

Additionally, patients presented a loss of interest in activities (for instance, reading, watching television), which meant that there was little common ground for them to talk; "She's no interest in the telly. She'd be sitting here, looking up this way but the television is over there. She used to look at half-hour programs, now she's no interest in them at all"; "There's no use in discussing things with him".

However, despite these difficulties, some did find opportunities for meaningful interactions. For example preservation of remote memories provided opportunities to remi- nisce over old photographs; "She's beginning to remember her old life now because she can't rely on the present...so I'd take out the old photographs, from when we were married". Some caregivers also found opportunities for shared experiences, such as listening to music or going to the park, which allowed for meaningful opportunities to interact; "We sat in the shade watching the sea-lions, children and all that, she likes where there's activity going on and she can watch"; "She's mad to go out anywhere, she's happy sitting in the car, travelling".

\section{Previous 'relationship' research}

More work is needed to explore how ICT can support communication between the caregiver and their partner at home. The preservation of long-term memory in dementia is widely acknowledged, and current methods in reminiscence therapy in care settings utilise old photos and mementos to stimulate memories. Alm et al. ${ }^{36}$ developed the CIRCA (Computer Interactive Reminiscence and Conversation Aid) which includes a 20-inch touch screen that allowed the users to navigate their way around reminiscence material related to different themes (for instance, recreation, entertainment and local history). The material was presented using different media types (for instance, photo, videos and music). The technology was designed to support communication between care workers and persons with dementia in residential care settings. Observational analysis revealed that the technology has some advantages over traditional reminiscence approaches. For example, the person with dementia tended to participate more in the conversation, and take direction of reminiscence topics. The system also offered significantly more choice to the person with dementia regarding conversation topics $^{36,37}$. Such systems could be further developed to facilitate interaction between the person with dementia and their family caregiver in the home setting. Such intervention would help maintain the relationship between the caregivers and their partners, which can help reduce the negative impact of care demands. 


\section{Caregivers and $\| C T$}

\section{Identifying caregiver requirements}

The high-level characterisation of the problems experienced by caregivers is useful for engineers and designers involved in the development of ICT. Many of the issues raised will already be familiar with researchers and clinicians in this area, and confirm approaches already taken in ICT design. For example, accessible content related to dementia care and local support services have already been made available in existing systems. The home visit interviews revealed the need to also encourage the caregiver to manage their own mental and physical wellbeing. These subtle, but important, requirements would have positive consequences for the caregiver ability to continue their role. The analysis also demonstrates the need to extend the focus beyond information provision and social support. ICT should help caregivers sustain existing social networks using lightweight communication tools (for instance, messaging, photo sharing and awareness displays), which are unobtrusive and require little attention. This is compatible with the ongoing demands of the caring role, which essentially underlie the problems of social isolation. Finally, the home visit interviews allowed participants to express day-to-day concerns and experiences of living with a person with dementia. This revealed the important issue of the patientcaregiver relationship and the difficulties in communication. It is apparent that ICT could potentially have a role in supporting interactions between the caregiver and care recipient, thus supporting the maintenance of the spousal relationship. This could be a meritorious goal around which to base an ICT design for caregivers.

Loneliness is a subjective state of negative affect associated with perceived social iso-

\section{Acknowledgements}

The authors would like to acknowledge Dr Cathal Walsh of the Department of Statistics, Trinity College Dublin, for his statistical advice, Dr Roman Romero-Ortuno, St James's Hospital, Clodagh Cunningham for her role in recruitment, the research team involved in data collection, and the individuals who participated in lation $^{38}$. This can stem from the absence of a broader group of contacts engaging social network, often referred to as 'social loneliness'. However, it can also arise from the absence of an intimate relationship or close attachment, which is often referred to as 'emotional loneliness'. These states occur independently, which means that a person may suffer from loneliness despite being surrounded by many people ${ }^{39}$. Furthermore, emotional loneliness alone has been found to impact health status among older adults ${ }^{40}$, and so is important for enabling caregivers to maintain their role. To date ICT solutions have focused on providing social support and contact with broader social networks. Although these are important, there is also need to support communication with their spouse and help maintain some companionship. This illustrates the value of the grounded theory approach to identify further opportunities to support users.

\section{Conclusions}

This paper has provided a detailed account of the problems reported by spousal caregivers living with a person with dementia. The home visit interviews and grounded theory analysis were useful for informing the design of ICT. The results confirm the importance of information provision and social support, currently being addressed, which has currently been the focus of most ICT solutions for caregivers. However, our informants' accounts also highlight the need to help caregivers maintain social connectedness with family and friends in flexible and unobtrusive ways. Additionally, technology should be designed to facilitate communication between the caregiver and the person with dementia in the home setting. These additional areas of support will help reduce caregiver burden and perceived ability to cope.

TRIL research. This research was completed as part of a wider programme of research within the TRIL Centre, (Technology Research for Independent Living).

The TRIL Centre is a multi-disciplinary research centre, bringing together researchers from University College Dublin, Trinity College Dublin, National University of Ireland at Galway, and 


\section{Caregivers and ICT}

Intel, funded by Intel, Industrial Development Agency Ireland and General Electrics Healthcare.

\section{References}

1. Burns A, Rabins P. Carer burden in dementia. International Journal of Geriatric Psychology 2000;15(1):9-13; doi:10.1002/1099-1166(200007)15

2. Knapp M, Prince M. Dementia UK: Personal Social Services Research Unit, 2007; www.alzheimers.org.uk/site/scripts/download_info.php?fileID=2; retrieved November 20, 2008

3. Hope T, Keene J, Gedling K, Fairburn CG, Jacoby R. Predictors of institutionalization for people with dementia living at home with a carer. International Journal of Geriatric Psychology 1998;13(10):682-690; doi:10.1002/ (SICI)1099-1166(1998100)13:10<682::AIDGPS847>3.0.CO;2-Y

4. Chenoweth B, Spencer B. Dementia: the experience of family caregivers. Gerontologist 1986;26(3):267-272; doi:10.1093/ geront/26.3.267

5. McCurry SM, Logsdon RG, Teri L, Vitiello MV. Sleep disturbances in caregivers of persons with dementia: Contributing factors and treatment implications. Sleep Medicine Review 2007;11(2):143-153; doi:10.1016/j.smrv.2006.09.002

6. Beeson R. Loneliness and depression in spousal caregivers of those with Alzheimer's disease versus non-caregiving spouses. Archives of Psychiatric Nursing 2003;17(3):135-143; doi:10.1016/S08839417(03)00057-8

7. Jepson C, McCorkle R, Adler D, Nuamah I, Lusk, E. Effects of home care on caregivers' psychosocial status. Journal of Nursing Scholarship 1999;31(2):115-120;doi:10.1111 /j.1547-5069.1999.tb00444.x

8. Graff MJL, Vernooij-Dassen MJ, Zajec J, Olde Rikkert MGM, Hoefnagels WHL, Dekker J. How can occupational therapy improve the daily performance and communication of an older patient with dementia and his primary caregiver? A case study. Dementia 2006; 5(4):503-532; doi:10.1177/1471301206069918

9. Moritz DJ, Kasl SV, Berkman LF. The Health Impact of Living With a Cognitively Impaired Elderly Spouse: Depressive Symptoms and Social Functioning. Journal of Gerontology 1989;44(1):17-27; doi:10.1093/geronj/44.1.S17

10. Schultz CL, Smyrnios KX, Schultz NC, Grbich CF. Longitudinal outcomes of psychoeducational support for family caregivers of elderly dependent persons. Australian Psychologist 1994;28(1):21-24; doi:10.1080/00050069308258859

11. Ostwald SK, Hepburn KW, Caron W, Burns T, Mantell R. Reducing caregiver burden: A randomized psychoeducational intervention for caregivers of persons with dementia. Gerontologist 1997;39(3):299309; doi:10.1093/geront/39.3.299

12. Gonyea JG, Silverstein NM. The role of Alzheimer's disease support groups in families' utilization of community services. Journal of Gerontology and Social Work 1991;16(3/4):43-55; doi:10.1300/ J083v16n03_05

13. Brennan PF, Moore SM, Smyth KA. The effects of a special computer network on caregivers of persons with Alzheimer's disease. Nursing Research 1995;44(3):166-172; doi:10.1097/00006199-199505000-00007

14. Czaja SJ, Rubert MP. Telecommunications technology as an aid to family caregivers of persons with dementia. Psychosomatic Medicine 2002;64(3):469-476; www.soc.duke. edu/courses/soc163/articles/Support_3.1.pdf; retrieved February 24, 2012

15. Glueckauf RL, Ketterson TU, Loomis JS, Dages P. Online support and education for dementia caregivers: overview, utilization, and initial program evaluation. Telemedicine Journal and E-Health 2004;10(2):223232; doi:10.1089/tmj.2004.10.223

16. Marziali E, Donahue P. Caring for others: Internet video-conferencing group intervention for family caregivers of older adults with neurodegenerative disease. Gerontologist 2006;46(3):398-403; doi:10.1093/ geront/46.3.398

17. Roest HG van der, Meiland FJM, Jonker C, Dröes R. User evaluation of the DEMentia-specific Digital Interactive Social Chart (DEM-DISC). A pilot study among informal carers on its impact, user friendliness and usefulness. Aging and Mental Health 2010;14(4):461-470; doi:10.1080/13607860903311741

18. Powell J, Chiu T, Eysenbach G. A systematic review of networked technologies supporting carers of people with dementia. Journal of Telemedicine and Telecare 2008;14(3):154-156; doi:10.1258/ jtt.2008.003018

19. Strauss AL, Corbin J. Basics in qualitative research. London: Sage, 1990

20. Wherton JP, Monk AF. Technological opportunities for supporting people with dementia who are living at home. Internal Journal of Human-Computer Studies 2008;66(8):571-586; doi:10.1016/j. ijhcs.2008.03.001

21. Burton LC, Newsom JT, Schulz R, Hirsch $\mathrm{CH}$, German, PS. Preventive health behaviours among spousal caregivers. Preventive 


\section{Caregivers and $\| C T$}

Medicine1997;26(2):162-169; doi:10.1006/ pmed.1996.1029

22. Schulz R, Newsom J, Mittelmark M, Burton L, Hirsch C, Jackson S. Health effects of caregiving: The caregiver health effects study: An ancillary study of the Cardiovascular Health Study. Annals of Behavioural Medicine 1997;19(2):110-116; doi:10.1007/ BF02883327

23. Connell CM. Impact of spouse caregiving on health behaviours and physical and mental health status. Alzheimer Disease and Associated Diseases 1994;1(9):26-36; doi:10.1177/153331759400900105

24. Spitznagel MB, Tremont G, Davis J, Foster

S. Psychosocial predictors of dementia caregiver desire to institutionalize: Caregiver, care recipient, and family relationship factors. Journal of Geriatric Psychology and Neurology 2006;19(1):16-20; doi:10.1177/0891988705284713

25. Gonyea JG, O'Connor M, Carruth A, Boyle PA. Subjective appraisal of Alzheimer's disease caregiving: The role of self-efficacy and depressive symptoms in the experience of burden. Alzheimer Disease and Associated Diseases 2005;20(5):273-280; doi:10.1177/153331750502000505

26. Bandura A. Social Learning Theory. New York: General Learning Press; 1977

27. Haley WE, West CA, Wadley VG, Ford GR, White FA, Barrett JJ, Harrell LE, Roth DL. Psychological, social, and health impact of caregiving: a comparison of black and white dementia family caregivers and non-caregivers. Psychology and Aging 1995;10(4):540552; doi:10.1037/0882-7974.10.4.540

28. Gold DP, Cohen C, Shulman K, Zucchero C, Andres D, Etezadi J. Caregiving and dementia: predicting negative and positive outcomes for caregivers. International Journal of Aging and Human Development 1995;41(3):183-201; doi:10.2190/RGYJ5KA2-7THX-7BQ5

29. Clyburn LD, Stones MJ, Hadjistavropoulos T, Tuokko, H. Predicting caregiver burden and depression in Alzheimer's disease. Journal of Gerontology B: Psychology 2002;55(1):2-13; doi:10.1093/geronb/55.1.S2

30. Orpwood R, Gibbs C, Adlam T, Faulkner $\mathrm{R}$, Meegahawatte $\mathrm{D}$. The design of smart homes for people with dementia: User interface aspects. Universal Access in the Information Society 2005;4(2):156-164; doi:10.1007/s10209-005-0120-7

31. Dunk B, Doughty K. The Aztec projects: providing assistive technology for people with dementia and their carers in Croydon. In: Proceedings 2nd Laing and Buisson 2006 Telecare and Assistive Technology
Conference. London; January 2006; pp 1-11; www.alzheimers-support.com/.../ case-study-the-aztec-project.pdf; retrieved February 24, 2012

32. Wherton JP, Prendergast DK. Building bridges: Involving older adults in the design of communication technology to support peer-to-peer social engagement. In: Holzinger A, Miesenberger K, editors. $\mathrm{HCl}$ and Usability for E-Inclusion. Berlin: Springer; 2010; pp 111-134

33. Hindus D, Mainwaring SD, Leduc N, Hagstro AE, Bayley O. Casablanca. Designing social communication devices for the home. In: Proceedings of the 2001 ACM Conference on human factors in computing systems; CHI 2001. New York: ACM; 2004; pp 325-332; doi:10.1.1.131.9063

34. Mynatt ED, Rowan J, Craighill S, Jacobs A. Digital family portraits: Providing peace of mind for extended family members. In: Proceedings of the 2001 ACM Conference on human factors in computing systems; CHI 2001. New York: ACM; 2001; pp 333340; doi:10.1145/365024.365126

35. Morris M, Lundell J, Dishman E. Catalyzing social interaction with ubiquitous computing: A needs assessment of elders coping with cognitive decline. In: Proceedings of the 2004 ACM Conference on human factors in computing systems; CHI 2004. New York: ACM; 2004; pp 1151-1154; doi:10.1145/985921.986011

36. Alm N, Astell A, Ellis M, Dye R, Gowans G, Campbell J. A cognitive prosthesis and communication support for people with dementia. Neuropsychological Rehabilitation 2004;14(1/2):117-134; doi:10.1080/09602010343000147

37. Alm N, Dye R, Gowans G, Campbell J, Astell A, Ellis M. A communication support system for older people with dementia. Computer 2007;40(5):35-41; doi:10.1109/MC.2007.153

38. Wenger GC, Davies R, Shahtahmasebi $\mathrm{S}, \mathrm{Scott}$ A. Social isolation and loneliness in old age: Review and model refinement. Ageing Society 1996;16(3):333-358; doi:10.1017/S0144686X00003457

39. Victor CR, Scambler SJ, Shah S, Cook DG, Harris T, Rusk E, Wilde S de. Has loneliness amongst older people increased? An investigation into variations between $\mathrm{CO}-$ horts. Ageing and Society 2002;22(5):585597; doi:10.1017/S0144686X02008784

40. Sorkin D, Rook S, Lu JL. Loneliness, lack of emotional support, lack of companionship, and likelihood of having a heart condition in an elderly sample. Annals of Behavioural Medicine 2002;24(4):290-298; doi:10.1207/ S15324796ABM2404_05 